\title{
ANALISIS PROSES PERENCANAAN PROGRAM PENDIDIKAN NONFORMAL BAGI ANAK JALANAN DI KLINIK JALANAN SAMARINDA
}

\author{
Mustangin* \\ Program Studi Pendidikan Luar Sekolah, Universitas Mulawarman \\ *Email: mustangin1992@gmail.com
}

\begin{abstract}
Street children become one of the problems that exist today, so it needs non-formal education efforts through its programs to overcome these problems. To get maximum educational results, a non-formal education program planning strategy is needed for these street children. This study aims to analyze the planning process of non-formal education programs for street children in Klinik Jalanan Samarinda. This study uses a qualitative approach because it will reveal how the non-formal education program planning process is for street children. This type of research is a descriptive study that will produce a description of the focus of the research conducted. Data collection techniques using interviews, observation, and study of documents. While the data analysis technique uses data reduction, data presentation, and drawing conclusions. The analyzing the validity of the data using data triangulation. The results of the study revealed that the planning process carried out by the Klinik Jalanan Samarinda was divided into several processes including the approach to street children as a means of learning citizens. The next process is identifying the learning needs of street children to design non-formal education programs such as what is suitable for street children. Next is the preparation of learning to get an agreement with street children because street children have their preoccupations, so the need for an agreement on the time and place for the implementation of learning.
\end{abstract}

Keywords: street childreen, education, non-formal education, planning programs

\section{PENDAHULUAN}

Permasalahan anak jalanan masih menjadi permasalahan yang masih dihadapi oleh bangsa ini. Anak jalanan sering dipandang sebagai komunitas yang negatif di masyarakat saat ini. Puruhita, Suyahmo dan Atmaja (2016) mengungkapkan bahwa pendapat yang berkembang dalam masyarakat mengenai anak jalanan merupakan sesuatu yang negatif. Selain itu Armita (2016) mengungkapkan bahwa di wilayah masyarakat kota, keberadaan anak jalanan menjadi suatu realitas kehidupan sehingga anak jalanan menjadi semakin tidak mendapatkan makna hidup dan apresiasi positif dalam hubunganhubungan sosial budaya dengan masyarakat kota pada umumnya Selain itu komunitas anak 
jalanan ini juga termasuk salah satu komunitas dari kalangan menengah ke bawah atau berasal dari komunitas miskin. Astri (2014) mengungkapkan bahwa keberadaan anak jalanan dilatarbelakangi oleh kemiskinan, penyimpangan kepribadian, dan faktor luar dari anak jalanan tersebut selain itu fakta di lapangan mengungkapkan bahwa sebagian besar anak jalanan memang berasal dari keluarga miskin. Hal tersebut membuktikan bahwa kondisi yang terjadi pada anak jalanan saat ini berada dalam permasalahan sosial dan ekonomi

Upaya mengatasi permasalahan anak jalanan tersebut dapat dilaksanakan melalui upaya pendidikan bagi anak jalanan. Fatoni (2020) mengungkapkan bahwa Pendidikan menduduki posisi sentral dalam pembangunan karena sasarannya adalah peningkatan kualitas sumber daya manusia. Selain itu Sukmaningrum dan Faizah (2019) mengungkapkan bahwa apabila anak-anak sudah turun di jalanan dan bekerja, maka mereka akan kehilangan masa kanakkanaknya serta kesempatan untuk mendapatkan pendidikan yang lebih tinggi, sehingga diragukan kualitasnya dalam menyongsong masa depan. Pendidikan adalah upaya meningkatkan pengetahuan dan keterampilan bagi anak jalanan sehingga anak jalanan tersebut memiliki bekal untuk menghadapi permasalahannya tersebut. Berdasarkan Undang-undang No. 20 Tahun 2003 tentang sistem pendidikan nasional menyatakan bahwa salah satu pendidikan yang ada di Indonesia adalah pendidikan nonformal. Pendidikan nonformal merupakan pendidikan yang tepat untuk memfasilitasi anak jalanan untuk mendapatkan layanan pendidikan. Pendidikan nonformal dilaksanakan sesuai dengan kebutuhan masyarakat sasaran khususnya anak jalanan. Selain itu juga anak jalanan banyak yang termasuk ke dalam anak yang putus sekolah. Alasannya adalah anak jalanan tidak memiliki waktu untuk sekolah formal dan dikarenakan kesulitan perekonomian sehingga anak jalanan tidak bersekolah pada pendidikan formal.

Pendidikan nonformal dapat dilaksanakan bagi semua kalangan yang membutuhkan layanan pendidikan untuk meningkatkan keterampilan dan pengetahuan. Pendidikan nonformal dilaksanakan melalui program-program yang disesuaikan dengan kebutuhan pendidikan untuk anak jalanan itu sendiri. Berdasarkan hal tersebut maka perlu ada perencanaan program pendidikan nonformal agar mampu memberikan layanan yang dibutuhkan oleh masyarakat sasaran khususnya anak jalanan. Adanya perencanaan program pendidikan nonformal maka akan memudahkan pelaksana program pendidikan nonformal untuk melaksanakan program pendidikan nonformal tersebut. Sehingga perencanaan program pada pendidikan nonformal menjadi sangat penting untuk mendapatkan hasil yang maksimal.

Hasil studi lapangan yang telah dilaksanakan, salah satu pelaksana pendidikan nonformal adalah Klinik Jalanan Samarinda. Berdasarkan laporan penelitian yang dilaksanakan oleh Anwar (2016) diketahui bahwa Klinik Jalanan 
Samarinda mengembangkan model-model pendekatan humanis yang lebih memanusiakan anak-anak jalanan selain itu tidak ada tanda-tanda model penangananan represif pada klinik ini, Klinik Jalanan Samarinda memiliki fokus pendidikan bagi anak jalanan dengan membuat program pendidikan nonformal bagi anak jalanan, seperti kegiatan pelatihan dan lainnya. Program-program tersebut pastilah memiliki perencanaan sehingga program dapat terlaksana dengan baik. Berdasarkan realita tersebut maka fokus yang menjadi kajian ini adalah bagaimana proses perencanaan program pendidikan nonformal pada Klinik Jalanan Samarinda. Sehingga dari kajian ini akan diperoleh sebuah analisis perenanaan pendidikan nonformal bagi anak jalanan di Klinik Jalanan Samarinda.

\section{METODE PENELITIAN}

\section{Desain Penelitian}

Penelitian ini menggunakan metode deskriptif dengan pendekatan kualitatif. Alasan Pendekatan kualitatif dipilih sebagai pendekatan dalam penelitian karena sesuai dengan tujuan penelitian yang telah dirumuskan yaitu untuk menganalisis secara detail dan rinci mengenai bagaimana proses perencanaan program pendidikan nonformal bagi anak jalanan di Klinik Jalanan Samarinda. Cresswell (2013) menyatakan bahwa melakukan penelitian kualitatif perlu mengkaji masalah yang kompleks selain itu perlu pemahaman yang lebih rinci tentang topik yang diangkat dalam penelitian. Oleh karena itu, data yang akan dikumpulkan lebih spesifik membutuhkan penggalian data secara mendalam mengenai proses perencanaan program pendidikan nonformal bagi anak jalanan di Klinik Jalanan Samarinda.

Metode penelitian yang dipilih oleh peneliti adalah menggunakan metode deskriptif. Metode ini dipilih karena pada penelitian ini akan mendeskripsikan secara lebih detail dan rinci hasil analisis tentang proses perencanaan program pendidikan nonformal bagi anak jalanan di Klinik Jalanan Samarinda.

\section{Teknik Pengumpulan Data}

Pengumpulan data merupakan langkah yang paling strategis dalam pelaksanaan penelitian ini. Pengumpulan data dilaksanakan oleh peneliti selama melaksanakan kegiatan penelitian. Pengumpulan data yang dilaksanakan menggunakan teknik pengumpulan data seperti Wawancara, Observasi, dan Studi Pendahuluan. Secara lebih rinci penjelasan tentang teknik pengumpulan yang dilaksanakan untuk memperoleh data pada penelitian ini, adalah sebagai berikut:

1. Wawancara

Pengumpulan data melalui wawancara merupakan salah satu pengumpulan data yang utama dalam penelitian ini. Jenis data yang akan diperoleh dari penelitian ini adalah data yang berupa kata-kata yang akan didapat dari kegiatan tanya jawab antara peneliti dengan informan. Informan kunci yang 
diwawancarai seperti yang telah dibahas sebelumnya yaitu Pengelola Klinik Jalanan, Pendidik, dan Anak Jalalan sebagai peserta didik yang ada di Klinik Jalanan Samarinda.

2. Observasi

Peneliti bertindak langsung kelapangan untuk melakukan observasi dengan mengamati kegiatan-kegiatan pendidikan yang ada di Klinik Jalanan. Observasi yang dilakukan peneliti digunakan untuk mendukung data utama yang didapat dari wawancara sehingga data yang didapat akan lebih akurat.

3. Studi Dokumen

Studi dokumen yang dilakukan peneliti berupa studi mengenai dokumendokumen yang terkait dengan penelitian yang akan dilakukan. Jenis data yang akan dikumpulkan melalui studi dokumen ini adalah data yang berupa sumbersumber tertulis dan foto-foto terkait dengan topik penelitian. Studi dokumen ini dilakukan untuk memperkuat data hasil wawancara. Hal ini dilakukan oleh peneliti karena untuk mendukung data agar lebih akurat.

\section{Teknik Analisis Data}

Analisis data kualitatif adalah upaya yang dilakukan dengan jalan bekerja dengan data, menorganisasikan data, memilah-milahnya, mencari dan menemukan pola, menemukan apa yang penting untuk dilaporkan sebagai hasil penelitian. Teknik analisis data pada penelitian ini mengacu pada Milles \& Huberman (dalam Sugiyono 2010) yang terbagi dalam tiga langkah, yaitu:

1. Reduksi data (Data Reduction)

Reduksi data yaitu suatu proses pemilahan, pemusatan perhatian pada penyederhanaan, pengabstrakan dan transformasi data kasar yang muncul dari catatan-catatan tertulis di lapangan. Dalam penelitian proses reduksi data adalah Pertama, data yang didapat dari wawancara merupakan data mentah. Selanjutnya peneliti memilah-milah data yang dikumpulkan. Kedua, setelah data dipilah-pilah peneliti melakukan pengkodean data, artinya mengkodekan data menggunakan simbol, berdasarkan informan dan waktu wawancara untuk mempermudah mencari data. Ketiga, data yang sudah diberi kode, kemudian disesuaikan dengan fokus penelitian.

2. Penyajian data (Display Data)

Setelah data dipilah-pilah dan disesuaikan dengan fokus penelitian maka peneliti melakukan penyajian data. Peneliti menyajikan data yang bermakna tersebut dalam bentuk narasi atau uraian yang lebih mudah dipahami dan lebih komunikatif

3. Penarikan kesimpulan (Verifikasi)

Setelah data disajikan peneliti melakukan penarikan kesimpulan awal berdasarkan hasil temuan data. Setelah data diverifikasi berdasarkan buktibukti yang kuat dan konsisten dengan kondisi saat dilakukan penenlitian, 
maka peneliti menarik kesimpulan sebagai kesimpulan akhir sesuai dengan tujuan penelitian yang telah ditetapkan

\section{Teknik Analisis Keabsahan Data}

Peningkatan kesahihan (keabsahan) data, peneliti menggunakan beberapa teknik keabsahan data. Analisis kesahihan data dilakukan agar data penelitian untuk tesis ini benar-benar sesuai dengan kondisi yang ada di lapangan. Pada penelitian ini, pengecekan keabsahan data dilakukan dengan Triangulasi Sumber dan Triangulasi Teknik. Triangulasi Sumber dilaksanakan dengan cara peneliti membandingkan data yang diperoleh melalui hasil wawancara mendalam. Triangulasi teknik dilakukan dengan mengecek hasil wawancara, observasi dan studi dokumen.

\section{HASIL DAN PEMBAHASAN}

Pendidikan Nonformal terlebih dahulu dilakukan perencanaan program, terutama pada program konservasi lingkungan ini. Pentingnya perencanaan program bertujuan agar didapatkan hasil yang maksimal. Terlebih program pendidikan nonformal merupakan program yang berbasis kebutuhan masyarakat sasaran, sehingga perlu persiapan yang matang juga. Oleh karena itu maka posisi tahapan perencanaan program ini penting untuk dilaksanakan.

\section{Proses pendekatan kepada anak jalanan}

Pada pelaksanaan program pendidikan nonformal hal yang dilakukan salah satunya adalah pendekatan kepada calon warga belajar. Hal ini seperti yang diungkapkan oleh Raharjo (2018) bahwa tahap pendekatan ini dilaksanakan sebagai penjajagan awal sebelum melakukan kegiatan pembelajaran. Proses pendekatan dilaksanakan oleh klinik jalanan untuk mencari informasi dan pendataan anak jalanan diberbagai zona. Hal ini sesuai dengan hasil penelitian yang dilaksanakan oleh Syahid (2017) bahwa proses awal yang perlu dilakukan untuk pelaksanaan program adalah identifikasi sasaran calon warga belajar program pendidikan nonformal. Hal yang sama juga diungkapkan oleh Pamungkas (2017) bahwa Sebuah desain program pendidikan masyarakat dapat diadopsi sepenuhnya dalam merancang program pendidikan ada beberapa langkah diantaranya adalah penetapan kelompok sasaran atau warga belajar.

Proses pendekatan yang dilaksanakan oleh Klinik Jalanan Samarinda memiliki tujuan untuk mengetahui karakteristik anak jalanan yang akan menjadi sasaran kegiatan pendidikan yang akan dilaksanakan oleh Klinik Jalanan Samarinda sehingga Klinik Jalanan mengetahui karakteristik anak jalanan ada yang sangat terbuka ada pula memiliki ketakutan tersendiri dengan orang baru khususnya tim dari Anak Jalanan Samarinda. Hal ini sesuai dengan yang ditulis oleh Mustangin (2018) bahwa pada kegiatan perencanaan tahap pertama adalah mengenali peserta didik yang akan menjadi bagian dari kegiatan pembelajaran dengan tujuan untuk mengenali calon warga belajar sasaran program dan juga hal 
ini dilakukan untuk pemantapan dan penilaian terhadap karakteristik peserta didik.

Proses pendekatan warga belajar merupakan proses penjajakan awal yang dilaksanakan untuk melaksanakan program pendidikan nonformal. Proses ini juga dilaksanakan oleh klinik jalanan dengan tujuan mendapatkan informasi yang akurat tentang anak jalanan sebagai calon warga belajar Klinik Jalanan Jalanan Samarinda. Proses pendekatan kepada anak jalanan merupakan bagian awal dalam pelaksanaan yang disarankan untuk melaksanakan kegiatan pendidikan nonformal.

\section{Identifikasi Kebutuhan Belajar Anak Jalanan}

Program pendidikan nonformal dilaksanakan berdasarkan kebutuhan warga belajar, hal tersebut juga dilaksanakan oleh Klinik Jalanan Samarinda. Hal ini dikarenakan Pendidikan Non Formal (NFE) berkembang berdasarkan kebutuhan belajar manusia (Rahma, Zulkarnain, Desyanty dan Wahyuni, 2019). Proses identifikasi kebutuhan belajar anak jalanan samarinda dilaksanakan oleh Divisi RnD yang memang bertugas sebagai tim khusus dari Klinik Jalanan Samarinda untuk tujuan perancangan program yang pendidikan nonformal yang dilaksanakan oleh Klinik Jalanan Samarinda sesuai dengan kebutuhan anak jalanan itu sendiri. Irmawita (2018) juga mengungkapkan bahwa Perencanaan diawali dengan perumusan tujuan dengan mempertimbangkan kebutuhan warga belajar.

Berdasarkan hasil lapangan tersebut dapat disimpulkan bahwa proses identifikasi kebutuhan belajar anak jalanan untuk program pendidikan nonformal tidak melibatkan seluruh anak jalanan yang menjadi sasaran didik Klinik Jalanan Samarinda. Proses ini dilaksanakan melalui diskusi-diskusi antara beberapa anak jalanan dengan Tim dari Divisi RnD.

Proses identifikasi kebutuhan tersebut sesuai dengan yang diungkapkan oleh Sudjana (2004) bahwa dalam penyelenggaraan program pendidikan nonformal, penyelenggara kegiatan dapat menggunakan beberapa langkah diantaranya adalah identifikasi kebutuhan belajar yaitu melakukan identifikasi kebutuhan belajar yang dinyatakan oleh calon peserta didik sehingga kebutuhan belajar dapat diidentifikasi langsung dari calon peserta didik atau warga belajar. Proses identifikasi kebutuhan belajar pada klinik jalanan dilaksanakan melalui diskusi dengan warga belajar yaitu anak jalanan namun berdasarkan hasil lapangan tidak melibatkan seluruh peserta didik.

\section{Persiapan Pembelajaran}

Proses persiapan pembelajaran dilakukan dengan menjalin kesepakatan dengan warga belajar. Hal ini sesuai dengan hasil penelitian yang juga dilaksanakan oleh Suryana, Siswanto, dan Dismawanti (2016) bahwa proses pembelajaran yang dilaksanakan sebelumnya dilakukan dengan menjalin kesepakatan dengan warga belajar meliputi kesepakatan jadwal pertemuan untuk 
pelaksanaan kegiatan pembelajaran. Hasil penelitian yang sama juga diungkapkan oleh Putri dan Desmawati (2016) bahwa Pada pelaksanaan program dimulai dengan perencanaan atau persiapan pembelajaran yang salah satunya adalah menjalin kesepakatan dengan warga belajar untuk melaksanakan kegiatan pembelajaran. Hasil lapangan yang telah dibahas diatas membuktikan bahwa proses penyampaian kesepakatan dengan anak jalanan dimaksudkan untuk mempersiapkan anak jalanan agar dapat mengkuti kegiatan pendidikan nonformal yang dilaksanakan oleh Klinik Jalanan. Sehingga anak jalanan menjadi lebih siap untuk menerima kegiatan pembelajaran yang dilaksanakan oleh Klinik Jalanan Samarinda. Hal tersebut sama dengan yang diungkapkan oleh Hidayati, Setiawati, dan Sunarti (2018) bahwa untuk meningkatkan kehadiran warga belajar perlu dilakukan penjadwalan yang sesuai dengan kondisi warga belajar dan pemilihan waktu dilakukan semaksimal mungkin dapat diikuti oleh semua warga belajar tanpa harus merugikan mereka dengan meninggalkan pekerjaan, pemilihan waktu ini akan lebih baik jika melibatkan seluruh warga belajar dengan musyawarah agar kesepakatan penjadwalan dapat dipertanggungjawabkan secara bersama-sama.

Proses yang dilaksanakan oleh pihak Klinik Jalanan Samarinda terkait dengan menjalin kesepakatan dengan warga belajar merupakan bagian dari proses penyiapan warga belajar untuk dapat melaksanakan kegiatan pembelajaran. Proses ini penting untuk dilaksanakan karena untuk mendapatkan kesepakatan waktu belajar anak jalanan sehingga anak jalanan dapat mengikuti pembelajaran yang telah dirancang oleh Klinik Jalanan Samarinda. Anak jalanan menghabiskan waktunya di jalanan sehingga dalam merancang program pendidikan nonformal juga harus menyesuaikan dengan kondisi dari anak jalanan itu sendiri.

\section{SIMPULAN}

Pendidikan nonformal bagi anak jalanan merupakan pendidikan yang diselenggarakan oleh satuan lembaga nonformal yang dalam penelitian ini adalah Klinik Jalanan Samarinda bagi anak jalanan untuk membekali anak jalanan pengetahuan dan keterampilan. Perencanaan program pendidikan nonformal bagi anak jalanan di samarinda pada penelitian ini dikaji dalam beberapa hal, berdasarkan hasil penelitian dapat disimpulkan bahwa Perencanaan pendidikan nonformal bagi anak jalanan dilaksanakan dalam beberapa hal dimulai dari kegiatan pendekatan kepada anak jalanan sebagai calon warga belajar. Proses ini dilaksanakan untuk mendapatkan informasi mengenai karakteristik anak jalanan. Proses pendekatan kepada anak jalanan merupakan bagian awal dalam pelaksanaan yang disarankan untuk melaksanakan kegiatan pendidikan nonformal. Selanjutnya proses identifikasi kebutuhan belajar anak jalanan yang dimaksudkan untuk mengetahui kebutuhan belajar apa yang diperlukan oleh anak jalanan, proses ini penting dilakukan untuk merancang program pendidikan 
nonformal. Langkah berikutnya adalah persiapan pembelajaran anak jalanan untuk mempersiapkan jadwal belajar, karena anak jalanan memiliki kesibukan setiap harinya sehingga harus disesuaikan dengan kondisi anak jalanannya.

\section{SARAN}

Klinik Jalanan Samarinda telah melaksanakan program pendidikan nonformal hal ini dibuktikan dengan adanya studi awal penjejakan dan identifikasi kebutuhan serta penjadwalan kegiatan. Berdasarkan hal tersebut maka penelitian ini disarankan kepada pihak pemerintah dalam pelaksanaan kegiatan pendidikan anak jalanan perlu untuk melakukan perencanaan program meliputi kegiatan penjejakan, identifikasi kebutuhan, dan persiapan pembelajaran. Selain itu penelitian ini juga disarankan kepada peneliti selanjutnya untuk mengkaji lebih dalam setiap proses perencanaan ini dengan teori-teori lain.

\section{DAFAR PUSTAKA}

Anwar, S. (2016). Strategi Penguatan Kapasitas (Capacity Building) Di Klinik Jalanan Samarinda. eJournal Sosiatri-Sosiologi. Vol. 4 (4). Hal. 75-84

Armita, P. (2016). Meningkatkan Kesejahteraan Sosial Anak Jalanan dengan Teori Self Esteem. Jurnal PKS. Vol. 15 (4): Hal. 377-386

Astri, H. (2014). Kehidupan Anak Jalanan Di Indonesia: Faktor Penyebab, Tatanan Hidup, dan Kerentanan Berperilaku Menyimpang. Aspirasi: Jurnal Masalah-Masalah Sosial. Vol. 5 (2): Hal. 145-155

Cresswell, J.W. (2013). Qualitative Inquiry \& Research Design: Choosing Among Five Approaches. London: Sage Publication

Fatoni, A. (2020). Wawasan Pendidikan (Pendidikan dan Pendidik). Mida: Jurnal Pendidikan Dasar Islam. Vol. 3 (1): 65-79

Hidayati, A., Setiawati., \& Sunarti, V. (2018). Gambaran Strategi Pembelajaran Partisipatif Kegiatan Pembelajaran Bahasa Indonesia Program Paket B Di PKBM Tanjung Sari. Spektrum PLS: Jurnal Pendidikan Luar Sekolah, Vol. $1(1): 1-8$

Irmawita. (2018). Pengelolaan Program Pendidikan Nonformal Untuk Kelompok Masyarakat Lanjut Usia. Kolokium: Jurnal Pendidikan Luar Sekolah. Vol. 6 (1): $1-8$

Mustangin. (2018). Kajian perencanaan pendidikan orang dewasa pada program kesetaraan paket C PKMB Jayagiri Lembang. Jurnal Penelitian Ilmu Pendidikan. Vol. 11 (1): Hal 40-47

Pamungkas, A.H. (2017). Rancangan Pengembangan Program Pendidikan Kewirausahaan Berbasis Pendidikan Luar Sekolah. Prosiding Seminar Nasional Pendidikan Nonformal FKIP Universitas Bengkulu, Vol. 1 (1): 199206 
Puruhita, A.A, Suyahmo \& Atmaja, H.T. (2016). Perilaku Sosial Anak-Anak Jalanan di Kota Semarang. Journal of Educational Social Studies. Vol. 5 (2). Hal. 104-112

Putri, D.N.N \& Desmawati, L. (2016). Penyelenggaraan Program Kelompok Belajar Usaha Di PKBM Kartika Kabupaten Purbalingga. Journal of Nonformal Education, Vol. 2 (2): 128-134

Raharjo, K.M. 2018. Pemberdayaan Anak Jalanan Sebagai Upaya Penyadaran Belajar Melalui Pendidikan Kesetaraan Di Kota Samarinda. Jurnal Pendidikan Nonformal, Vol. 13 (2): 63-69

Rahma, R.A, Zulkarnain, Desyanty, E.S, \& Wahyuni, S. (2019). The Role of Community Learning Center (CLC) in Providing Nonformal Education Services Based on Entrepreneurship. Journal of Nonformal Education, Vol. 5 (2): $13-20$

Sudjana, D. (2004). Manajemen Program Pendidikan: Untuk Pendidikan Nonformal dengan Pengembang Sumber Daya Manusia. Bandung: Falah Production

Sugiyono. (2010). Metode Penelitian Bandung (Pendekatan Kuantitatif, Kualitatif, dan R\&D. Bandung: Alfabeta

Sukmaningrum, P.S \& Faizah, S.I. (2019). Penguatan Ekonomi Orang Tua pada Keluarga Anak Jalanan (Studi Kasus: Sanggar Alang-Alang Surabaya). Jurnal Sosial Humaniora (JSH). Vol. 12 (2): 66-76

Suryana, S. Siswanto, \& Dismawati, L. (2016). Model Pembelajaran Dan Evaluasi Program Pendidikan Kesetaraan Paket B Dan Paket C Di Kota Semarang. Edukasi, Vol. 1 (1): 1-11

Syahid, A. (2017). Teknik Identifikasi Program Paket C dalam Meningkatkan Keterampilan Fungsional Warga Belajar. Journal of Nonformal Education and Community Empowerment, Vol. 1 (1): 18-25

Undang-Undang Republik Indonesia Nomor 20 Tahun 2003 Tentang Sistem Pendidikan Nasional 